\title{
Research Article \\ Invertebrate communities and environmental conditions in a series of urban drainage ponds in Eastern Scotland: implications for biodiversity and conservation value of SUDS $^{\dagger}$
}

Robert A. Briers

School of Life, Sport and Social Sciences, Edinburgh Napier University, Edinburgh, UK

Correspondence: Dr. R. A. Briers, School of Life, Sport and Social Sciences, Edinburgh Napier University, Sighthill Campus, Edinburgh, EH11 4BN, UK

E-mail: r.briers@napier.ac.uk

Running head: Biodiversity of invertebrate communities in SUDS ponds

Keywords: aquatic ecology, freshwater ecosystems, monitoring, pollution, stormwater

\footnotetext{
${ }^{\dagger}$ This article has been accepted for publication and undergone full peer review but has not been through the copyediting, typesetting, pagination and proofreading process, which may lead to differences between this version and the Version of Record. Please cite this article as an 'Accepted Article', doi: [10.1002/clen.201300162].
}

\section{(C) 2013 WILEY-VCH Verlag GmbH \& Co. KGaA, Weinheim}

Received: March 1, 2013 / Revised: June 19, 2013 / Accepted: September 17, 2013 


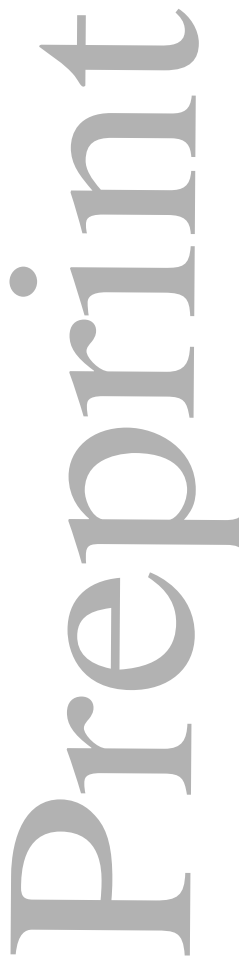

\begin{abstract}
Increasing use is being made of constructed wetlands to store and treat urban drainage prior to release into watercourses. Known as sustainable urban drainage systems (SUDS) in the UK these have potential to support and enhance freshwater biodiversity in urban areas, but the diversity and value of communities present in these ponds is not well-established. This study establishes the characteristics of invertebrate communities and investigates links with prevailing environmental conditions in four SUDS sites in Dunfermline, Scotland over a five-year period. The SUDS ponds supported communities of between 10 and 47 invertebrate species. Only one beetle species of conservation significance was recorded, along with an invasive species of mollusc. There were significant temporal changes in species richness and community composition, with the sites losing species and becoming more dissimilar over time. Variation in the invertebrate species composition at the sites was linked to both average environmental conditions and temporal variability, particularly soluble reactive phosphorus and dissolved oxygen levels. The biodiversity value SUDS of invertebrate communities may be limited by pollutant loads being received from drainage, but they can still potentially contribute to freshwater diversity in urban areas. In order to maximise their biodiversity potential, more research needs to be undertaken on appropriate design and management considerations.
\end{abstract}

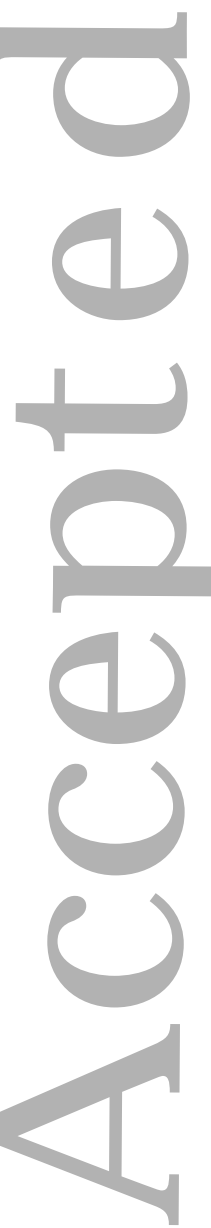

Abbreviations: CCA, canonical correspondence analysis; NMDS, non-metric multidimensional scaling; SRP, soluble reactive phosphorus; SUDS, sustainable urban drainage system;

\title{
1 Introduction
}

Urban drainage represents a significant source of pollution for freshwater ecosystems, containing a potent mixture of pollutants $[1,2]$. As part of integrated treatment of urban drainage, across the world increasing use is being made of constructed wetland systems (known as sustainable urban drainage systems - SUDS - in the UK) to store and treat water prior to release into watercourses [3-5]. Treatment of drainage water is generally through natural processes of sedimentation, absorption and conversion through uptake by microorganisms and plants [6], and there is active research into the design of systems to maximise effectiveness for treatment (e.g. [4, 7]). Such wetland and pond systems are primarily constructed for improving water quality and reducing the quantity of run-off to receiving watercourses. However, they also have the potential to contribute value in terms of amenity and biodiversity in urban areas, the final corner of the so-called 'SUDS Triangle' [8]. Through the majority of the last century there was a significant decline in pond numbers in the UK $[9,10]$, but more recently pond numbers have begun to increase although in recent years [10-12]. SUDS ponds, wetlands and other components may also help to redress the balance and act to support and enhance biodiversity in urban areas [13]. Given their significant role in storing and treating polluted urban drainage, the extent to which they can support biodiversity could be questioned. A limited number of studies have examined the biological diversity of SUDS ponds or similar structures such as highway stormwater management ponds. In general it has been found that they are capable of supporting a respectable number of species of both animals and plants [14-17]. Invertebrate 
community composition in freshwaters ecosystems is known to be influenced by environmental conditions; invertebrates form the basis of most of biotic indices of water quality e.g. [18, 19]. The diversity and composition of invertebrate communities may therefore be potentially limited by impacts of runoff which they are designed to treat, through exposure to pollutants and highly variable physico-chemical conditions due to temporal changes in the hydrological and pollutant load entering the sites [15, 16, 20-22]. There are also potential problems due to the unintentional introduction of invasive species of animals and plants with macrophytes stocked to aid their treatment function (notably Phragmites australis) [14, 23-25] or subsequent intentional introduction of invasive or non-native species. Almost all of the studies cited above focused on information gathered from 'snapshot' surveys undertaken in a single year or two years at the most. In order to be better able to determine the role of SUDS ponds in promoting freshwater biodiversity it is desirable to understand the extent of temporal change, particularly in respect to cumulative impacts of the nutrient and pollutant load that they are designed to treat.

The aims of the current study are therefore threefold: firstly to establish the composition and conservation value of invertebrate communities present in a series of urban drainage ponds in eastern Scotland. Secondly to analyse temporal trends in communities and the extent of between site differences and finally to examine the relationships between invertebrate community composition and the prevailing environmental conditions.

\section{Materials and methods}

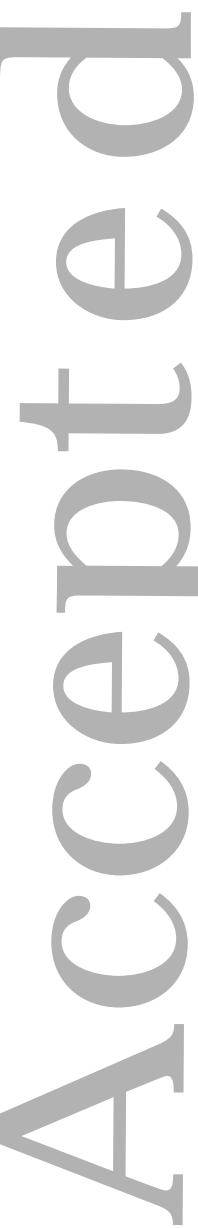

\subsection{Study sites}

The study sites were created as part of the integrated drainage system for a 750 ha mixed development on the east side of Dunfermline, Fife, Scotland, known as the Dunfermline East Expansion. Due to a combination of existing flooding and water quality issues in the area, an integrated suite of SUDS and other measures was established to treat all surface water drainage from the site. This study focuses on four sites which have been monitored in terms of water and sediment quality, along with initial work on invertebrate communities, since construction in 1997/8 (for more details see [3, 26, 27]). Table 1 gives a summary of the main characteristics of the sites studied. Three sites (Halbeath, Linburn and Pond 7) were constructed specifically for their SUDS role as site control elements. Calais Burn Wetland is a much larger site which was created by extending and modifying an existing wetland area. This site functions more as a regional control element in the water management system. Both Linburn and the Calais Burn Wetland receive water than has passed through upstream detention basins and other SUDS elements which in addition to slowing the rate of runoff discharge also remove at least some of the sediment and pollutant load. All sites have fairly steeply sloping sides with little in the way of a littoral zone, and have extensive marginal vegetation, predominantly P. australis. Beyond the marginal vegetation there is little in the way of significant habitat structure in either the water column or the benthos, although the Calais Burn Wetland site has several species of submerged macrophyte present in small areas ( $<5 \%$ surface area).

\subsection{Invertebrate sampling}

Invertebrates were sampled at the sites annually between 2007 and 2011 in July using a standard 3-minute pond net sample as per the methods used in the National Pond Survey in the UK [28]. Two samples were taken at each site in each year, roughly corresponding with the position of main inlet and outlet points. Sampled material 
was sorted in the laboratory to extract invertebrates, which were preserved in $70 \%$ industrial methylated spirits. In all years invertebrates were identified to species level, with the exception of oligochaetes, ostracods, some dipteran groups and immature/larval stages of Corixidae and Coleoptera which were identified to the lowest possible taxonomic level and enumerated. Superabundant taxa (Chironomidae, Asellidae and Potamopyrgus antipodarum) were enumerated in a series of volumetric subsamples $(3 \times 0.5 \mathrm{~L}$ from a total volume of $10 \mathrm{~L}$ mixed using an air pump), and then their total abundance derived by multiplication based on the mean number found in a subsample.

\subsection{Physico-chemistry}

A range of physico-chemical parameters were measured from each site in each year, in order to relate variation in invertebrate communities to the prevailing environmental conditions. Three replicate water samples were taken from each site contemporaneously to invertebrate sampling. In addition, similar replicate samples were also taken at approximately bi-monthly intervals throughout each year, in order to attempt to better characterise annual variability in conditions. Water samples were collected in $500 \mathrm{~mL}$ acid-washed polypropylene bottles and kept cool $\left(\sim 4^{\circ} \mathrm{C}\right)$ and in the dark prior to return to the laboratory. Conductivity and $\mathrm{pH}$ were measured from the field water samples at room temperature using laboratory meters (Hanna Instruments and Orion Research model 611, respectively) prior to freezing. The samples were then filtered using Whatman GF/F filters and frozen prior to analysis. Levels of nitrate, nitrite, ammonia and soluble reactive phosphorus (SRP) were determined using standard colourimetric techniques on a SEAL AQ2+ auto-analyser, with the exception of 2007, when manual determination using the same colorimetric methods was employed. Dissolved oxygen (percentage saturation) was measured in the field using a YSI model 95 meter. All samples were taken at approximately $15 \mathrm{~cm}$ depth and were taken at random time points during the day and in a random site order to avoid potential bias associated with consistent timing or order of sampling. A total of 172 samples were taken across all sites over the five-year period.

\subsection{Statistical analysis}

All analyses were undertaken using R version 2.14.2 [29]. Species richness, Shannon-Weaver diversity and Pielou's evenness were calculated for each sample, and temporal trends in each index examined using a mixedmodel ANOVA, incorporating a random site effect to account for repeated sampling of the same site over time. In addition to undertaking analysis of the whole community, separate analyses were performed on Coleoptera, Diptera, Hemiptera, Mollusca and Trichoptera. Other taxonomic groups recorded had insufficient species richness to allow analysis. Dissimilarity of invertebrate communities was assessed by calculating the BrayCurtis index between $\ln +1$ transformed abundances of all samples. Variation in dissimilarity of communities was summarised using non-metric multidimensional scaling (NMDS). Temporal and between site changes in similarity were assessed using distance-based permutational MANOVA, with year as a within-subjects effect. SIMPER analysis [30] was used to determine which species were the most important in driving between site differences in community composition.

Between-site differences in physico-chemical conditions were assessed using mixed-model ANOVA incorporating year as a random effect to account for repeated sampling (data for conductivity and all nutrients ln +1 transformed prior to analysis) and variability of environmental conditions assessed using Levene's test for 
equality of variances between different years at each site based on untransformed data.

Relationships between invertebrate community composition and the physico-chemical parameters measured were examined using canonical correspondence analysis (CCA). Given that the invertebrates present were potentially likely to be influenced by both the average conditions and the extent of variability over time, the mean and coefficient of variation of the physico-chemical parameters measured were used as predictors. Species abundance data, conductivity and nutrient level value were all ln +1 transformed prior to analysis. Forward selection of environmental variables ( $p<0.05$ for inclusion) was implemented and the overall significance of the final axes assessed using permutation tests.

\section{Results}

\subsection{Assessment of conservation value of invertebrate communities}

A total of 66 species of invertebrates were recorded across all sites, with the largest number of species recorded in the Coleoptera (17 species), Trichoptera (11 species) and Hemiptera (11 species) groups. Across all years, the species richness of sites varied between 10 and 47. Full details of the species present in the different sites are given in Supporting Information Table S1. Conservation value of the species present was determined by reference to the 2011 UK Joint Nature Conservation Committee Conservation Designation list, which incorporates national and international conservation designations. The Nationally Scarce beetle Hydroporus obsoletus, found at the Halbeath and Calais Burn Wetland sites, was the only species found with any conservation designation. This species was lost from Halbeath during the course of sampling (see below). A recognised invasive non-native species, the New Zealand mud-snail, Potamopyrgus antipodarum was also recorded at all sites except Halbeath.

\subsection{Temporal changes in species richness, diversity and similarity}

The Calais Burn Wetland site had substantially more species recorded than the other sites and Halbeath consistently the lowest species richness (Fig. 1). There was a significant change in species richness over time in all sites, showing a decline in the number of species recorded in each year (mixed-model ANOVA, $F_{[4,32]}=$ 7.437, $p=0.0002$, see Fig. 1). Some species were absent from a site in some years and reappeared in subsequent years which complicates analysis of species loss. Species lost were defined as those present for at least two of the first three years sampling and absent from the last two years. Table 2 summarises the species lost at different sites, mainly from the Coleoptera, Mollusca and Trichoptera groups. The Shannon-Weaver diversity index showed no significant variation across all sites over time (mixed-model ANOVA, $F_{[4,32]}=2.048, p=0.091$ ) whereas Pielou's evenness showed a significant increase (mixed-model ANOVA, $F_{[4,32]}=2.973, p=0.038$, see Fig. 1).

When analysed separately, there were significant declines in species richness of Trichoptera (mixed-model ANOVA, $\left.F_{[4,32]}=4.204, p=0.0075\right)$ and Mollusca $\left(F_{[4,32]}=3.046, p=0.031\right)$ and also a decline in in the diversity (Shannon index) of Trichoptera $\left(F_{[4,32]}=4.867, p=0.0035\right)$. Changes in species richness, diversity or evenness for all other taxon groups analysed were not significant.

In terms of similarity of community composition, there were clear differences evident between sites (Fig. 2), with the communities present at each site becoming increasingly dissimilar over time (permutational MANOVA, $F_{[12,19]}=8.1677, p<0.001$ ). Table 3 gives the top five taxa identified as contributing most 
substantially to the differences between the communities at each site through the SIMPER analysis.

\subsection{Physico-chemical variation}

Physico-chemical variables recorded at the sites are summarised in Table 4. There were significant between site differences in all parameters apart from conductivity. Sites also differed in the extent of variability of conditions recorded, notably in conductivity, dissolved oxygen, nitrite and SRP (Table 4).

\subsection{Species-environment relationships}

In the CCA, mean $\mathrm{pH}$, along with means and coefficient of variation of SRP and dissolved oxygen were retained in the analysis and the derived axes were highly significant (Monte Carlo significance test, $F=3.633, p=0.005$, explaining $45.5 \%$ of the variation in the species data and $75.7 \%$ of the species-environment relation). Figure 3 shows the distribution of sites and species in relation to the environmental variables. The invertebrate communities found at the sites formed fairly distinct groups in relation the environmental variation described by the CCA ordination in a similar manner to that shown in the NMDS analysis. The communities found at Halbeath and Linburn were both influenced by relatively low dissolved oxygen levels and low $\mathrm{pH}$ values. These two sites however are separated based on high variation in dissolved oxygen concentrations at Halbeath and high and variable SRP levels. The Calais Burn wetland site invertebrate community was linked to consistently higher $\mathrm{pH}$ values than the other sites (see also Table 4), whereas the Pond 7 invertebrate communities were

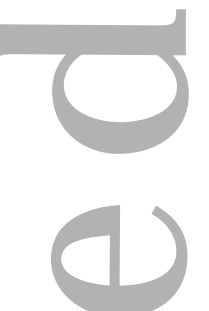
associated with low variability in dissolved oxygen, but greater variation in SRP. All sites showed some temporal variation in community composition in response to changes in physico-chemistry between years, with Linburn and Halbeath in particular showing variation that points to the influence of increasingly high levels of SRP and varying dissolved oxygen respectively. The increasing separation of the communities found at the sites over time is consistent with the patterns shown in the previous analysis of community dissimilarity.

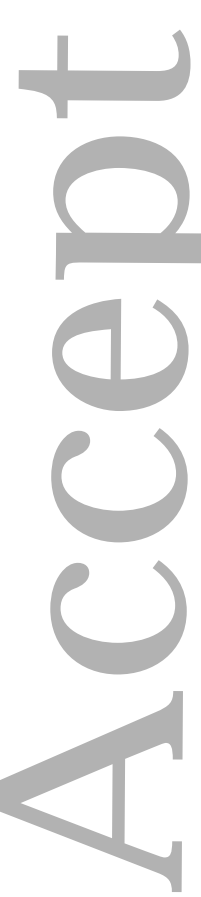

\section{Discussion}

Initial monitoring studies of the SUDS ponds considered here showed that they were rapidly colonised and developed invertebrate communities of between 10 and 28 species, over a period of five years after construction [27]. This rapid rate of colonisation is consistent with other studies of both SUDS ponds and ponds more generally, which indicate that fairly diverse communities can develop within two or three years [13, 31, 32]. Variation in the sampling techniques used in the initial studies [27] and the present study prevented direct comparison of the results, but levels of species richness at the start of the present study (ten years after construction) were comparable with those recorded previously. According to the national ranking developed based on the survey of minimally impaired sites that were sampled across the UK as part of the National Pond Survey [10] the relatively low species richness of these sites would place them in the Moderate conservation value category, with the exception of the Calais Burn Wetland site, which would come into the High category based on species richness. Only one species with conservation designation was recorded, the Nationally Scarce Hydroporus obsoletus, initially present at both Halbeath and Calais Burn Wetland, although lost from Halbeath during the period of sampling. This is lower than the national average for unimpaired ponds of 2.6 species per site [33]. This relatively low conservation value is not entirely unexpected based on the previous studies [14, 17]. The limited habitat diversity present at the sites and also the inputs of urban drainage waters that they are 
receiving are both likely to contribute to the limited conservation value. The presence of the invasive mollusc $P$. antipodarum at three of the sites has previously been linked to the stocking of $P$. australis as marginal vegetation [27]. High nutrient levels present in such urban waters has been linked to the success of invasive species [25] suggesting that this may be a consistent issue.

Without a full inventory of invertebrates from other nearby water bodies it is difficult to be sure as to the extent to which the invertebrate communities found contribute to overall freshwater biodiversity in the area. There are no other standing waters within $3 \mathrm{~km}$ of the sites studied, so whilst some generalist taxa found may be also found in nearby running waters, it seems likely that other more specialised standing water taxa have colonised the area from greater distances, either actively or passively [34] and hence the presence of the SUDS sites has resulted in an increase in overall freshwater biodiversity.

Differences in overall species richness between sites were consistent with previous data, with Calais Burn Wetland having higher species richness than all the other sites sampled and Halbeath the fewest species [13, 27]; the Calais Burn Wetland site is significantly larger (Table 1), and has a more complex morphology compared to the other sites. It was also created by excavating an existing marsh area to improve its function for treatment of drainage waters. Both these factors are likely to have influenced the greater levels of diversity found. However, over the course of the five years in which the current study was undertaken, there was a significant decline in species richness across all sites. Evenness also increased over the same period, suggesting that those species remaining had a more equitable abundance distribution. Diversity, as measured by the Shannon index, did not show any significant trend; given that this reflects both species richness and relative abundance patterns it is possible that these effectively cancelled each other out, resulting in no great change. On an individual taxonomic group basis, a significant decline in species richness was only evident for the Mollusca and Trichoptera groups, with the latter also showing a decline in diversity. Other groups showed no significant trend in any of the measures calculated. The overall decline in richness and increase in evenness would therefore appear to be due to relatively subtle changes in different taxonomic groups, which are only clearly evident when the overall community is analysed.

In addition to the changes in species richness, the sites also became increasingly dissimilar over time suggesting that their communities were gradually diverging in composition, at the same time as losing species overall. Some degree of variation in species composition between years is a natural characteristic of pond communities $[35,36]$ and diverging community composition and a decline in species richness can be associated with successional habitat changes [37, 38]. The steep bank profile and overall depth of the SUDS sites limits the extent to which marginal vegetation can encroach, and there is a relatively low sedimentation rate at the sites [3]. Therefore, the changes in species richness observed so do not appear likely to be explained by the very limited changes in the habitat structure. The greater extent of change demonstrated here appear to be linked to the overall levels and variation in pollutant loads over time. The sites showed substantial variation in both average values of different physico-chemical parameters and also the extent to which they varied over time (Table 4).

The importance of variation in environmental conditions, as well as average values, in the CCA results (Fig. 3) underscores the potential influence of temporally varying environmental conditions on pond invertebrate community development and change [37]. Nutrient levels (SRP), dissolved oxygen concentrations and pH were important predictors of community composition, with sites separating out along the environmental gradients. 
The Calais Burn Wetland had the highest and relatively stable oxygen concentrations, high $\mathrm{pH}$ and relatively low SRP levels. This relatively benign environment, in addition to the greater area and habitat diversity, may have influenced the greater diversity evident at this site. Temporal trends in species composition in the results of the CCA were particularly evident at the Halbeath and Linburn sites, which mirrored the changes in species richness and community similarity noted in earlier analyses, and similar characteristic species identified as important in distinguishing the sites in the CCA as in the SIMPER analysis. The sites are generally quite well separated in terms of environmental conditions (Fig. 3) which would tend to suggest that the gradual divergence of community dissimilarity and changes in species richness are linked to persistent trends in environmental conditions, notably high SRP and low oxygen levels. Similar links between invertebrate community composition and environmental parameters have been notes in other studies of similar sites e.g. [25], and the variables that were emphasised (SRP and dissolved oxygen particularly) are consistent with known influences on invertebrate communities across the range of freshwater ecosystems [39]. Other pollutants which were not assessed in the current study, such as heavy metals and hydrocarbons derived from road surfaces, are also potentially important in determining species composition and abundance in SUDS sites [21, 22, 33]. In these sites the levels of these pollutants found in sediment, at least up to 2006, was relatively low and stable [3], suggesting they are unlikely to be exerting a strong influence in comparison to the observed effects of SRP and oxygen concentration.

Urban drainage ponds clearly have a role to play in promoting local freshwater biodiversity. Although the communities that develop may be limited by the nutrient and other pollutant loadings that they receive, along with the limited habitat diversity that is commonly evident, they may still contribute significantly to overall diversity. Concerns have been raised over long-term sustainability of SUDS due to build-up of sediment and associated pollutants, which will eventually require to be disposed of $[3,40]$. On the basis that there were clear temporal trends of declining species richness across the sites studied, similar concerns can be raised over their value for biodiversity. If conditions gradually deteriorate due to build-up of pollutants then this will further restrict the diversity of invertebrate communities present. There have only been limited studies undertaken temporal trends in water and sediment quality in such sites. These have generally suggested that this may not be a significant issue over timescales of up to 11 years [3, 21], but the evidence here suggests a counter-argument in respect of the biodiversity value of SUDS, at least for invertebrates. In the longer-term, the need for sediment management and removal is also likely to result in significant disturbance on a periodic basis, impacting the communities of invertebrates supported by SUDS sites. Given the limited number of sites considered in the present study, the generality of the conclusions drawn here remains an open question requiring further investigation. Other studies have emphasised the need for long-term monitoring to better understand the patterns and processes involved in temporal change of invertebrate communities [38] and this is clearly also important in relation to the effectiveness of SUDS both as treatment systems and for biodiversity. Coupled with the present emphasis on research into the most effective design for treatment [4] should be similar considerations in relation to the biodiversity value of the systems. Some suggestions have already been made as to how to maximise the biological potential of SUDS [8, 24, 33] but there is a need for further study of the effectiveness of different measures. The SUDS studied here vary in terms of the extent of processing of water prior to discharge into the sites through the ‘treatment train’ [40]. Designing systems whereby there is sequential treatment of water as it passes through the system may enable SUDS towards the end of the process to support higher quality habitats. It 
may be fair to accept that a dual role for water treatment and biodiversity support may not be entirely compatible [15] but the careful design and management of systems should enable SUDS to achieve their maximum potential for both roles.

\section{Acknowledgements}

Taylor Woodrow and Fife Council gave permission to sample the sites. Thanks are also due to Fiona Culhane, Chris Hales, Long Lin, Michelle Yan, Luca Formigaro, Rhona Cairns, Jonathon Ferrier, John Kinross, Kate Heal and Teresa Fernandes for assistance with various parts of the field and lab work over the years. Parts of the sampling work were supported by a grant from the Carnegie Trust for the Universities of Scotland.

The author has declared no conflict of interest.

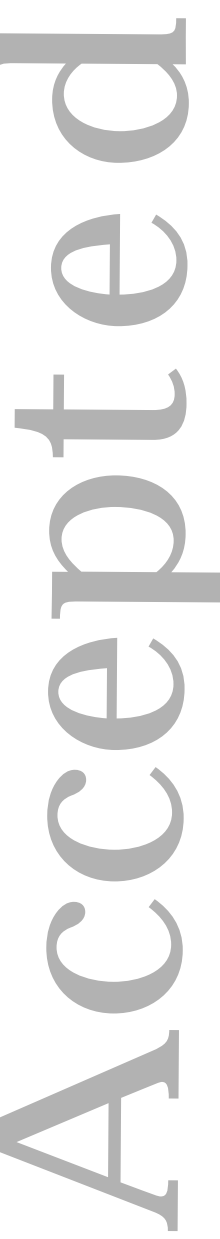




\section{References}

[1] M. J. Paul, J. L. Meyer, Streams in the urban landscape, Annu. Rev. Ecol. Syst. 2001, 32, 333-365.

[2] C. Wilson, R. Clarke, B. J. D'Arcy, K. V. Heal, P. W. Wright, Persistent pollutants urban rivers sediment survey: implications for pollution control, Water Sci. Technol. 2005, 51 (3-4), 217-224.

[3] K. Heal, D. A. Hepburn, R. J. Lunn, Sediment management in sustainable urban drainage system ponds, Water Sci. Technol. 2006, 53 (10), 219-227.

[4] M. Scholz, Wetland systems to control urban runoff, Elsevier, London 2006.

[5] A. H. Roy, S. J. Wenger, T. D. Fletcher, C. J. Walsh, A. R. Ladson, W. D. Shuster, H. W. Thurston, et al., Impediments and solutions to sustainable, watershed-scale urban stormwater management: Lessons from Australia and the United States, Environ. Manage.t 2008, 42 (2), 344-359.

[6] J. D. Weiss, M. Hondzo, M. Semmens, Storm water detention ponds: Modeling heavy metal removal by plant species and sediments, J. Environ. Eng. 2006, 132 (9), 1034-1042.

[7] S. G. Wallis, C. T. Morgan, R. J. Lunn, K. V. Heal, Using mathematical modelling to inform on the ability of stormwater ponds to improve the water quality of urban runoff, Water Sci. Technol. 2006, 53, 229236.

[8] B. Woods-Ballard, R. Kellagher, P. Martin, C. Jefferies, R. Bray, P. Shaffer, The SUDS Manual, CIRIA, London 2007.

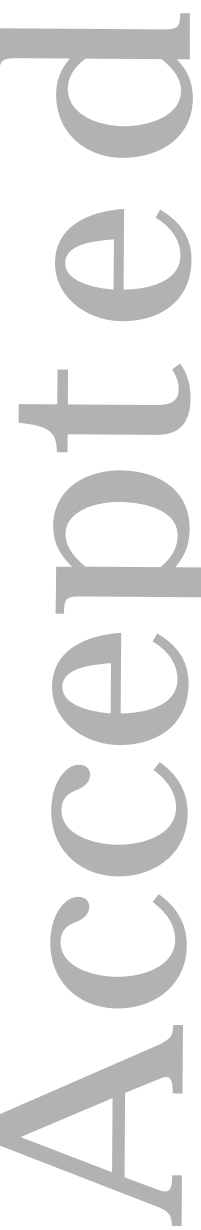

[9] P. J. Wood, M. T. Greenwood, M. D. Agnew, Pond biodiversity and habitat loss in the UK, Area 2003, 35 (2), 206-216.

[10] J. Biggs, P. Williams, M. Whitfield, P. Nicolet, A. Weatherby, 15 years of pond assessment in Britain: results and lessons learned from the work of Pond Conservation, Aquat. Conserv. Mar. Freshwater Ecosyst. 2005, 15, 693-714.

[11] P. J. Williams, J. Biggs, C. J. Barr, C. P. Cummins, M. K. Gillespie, T. C. G. Rich, A. Baker, et al., Lowland Pond Survey 1996, Department of the Environment, Transport and Regions, London 1998.

[12] P. Williams, J. Biggs, A. Crowe, J. Murphy, P. Nicolet, A. Weatherby, M. Dunbar, Countryside Survey: Ponds report from 2007, Technical Report No. 7/07, Pond Conservation and NERC/Centre for Ecology \& Hydrology, Wallingford Oxfordshire 2010.

[13] Ponds Conservation Trust: Policy and Research, An assessment of the ecological value of Sustainable Urban Drainage System ponds in Scotland, Ponds Conservation Trust: Policy and Research, Oxford 2000.

[14] Pond Action, An assessment of the ecological value of Sustainable Urban Drainage Systems in Scotland, Pond Action, Oxford 2000.

[15] L.-A. Hansson, C. Bronmark, A. N. Nilsson, K. Abjornsson, Conflicting demands on wetland ecosystem services: nutrient retention, biodiversity or both?, Freshwater Biol. 2005, 50, 705-714

[16] K. Vermonden, R. Leuven, G. van der Velde, M. M. van Katwijk, J. G. M. Roelofs, A. J. Hendriks, Urban drainage systems: An undervalued habitat for aquatic macroinvertebrates, Biol. Conserv. 2009, 142 (5), 1105-1115.

[17] I. Le Viol, J. Mocq, R. Julliard, C. Kerbiriou, The contribution of motorway stormwater retention ponds to the biodiversity of aquatic macroinvertebrates, Biol. Conserv. 2009, 142 (12), 3163-3171. 
[18] H. A. Hawkes, Origin and development of the Biological Monitoring Working Party score system, Water Res. 1997, 32, 964-968.

[19] N. Menetrey, B. Oertli, J. B. Lachavanne, The CIEPT: A macroinvertebrate-based multimetric index for assessing the ecological quality of Swiss lowland ponds, Ecol. Indic. 2011, 11 (2), 590-600.

[20] O. Scher, P. Chavaren, M. Despreaux, A. Thiery, Highway stormwater detention ponds as biodiversity islands?, Arch. Sci. 2004, 57 (2-3), 121-130.

[21] R. E. Casey, J.A. Simon, S. Atueyi, J. W. Snodgrass, N. Karouna-Renier, D. W. Sparling, Temporal trends of trace metals in sediment and invertebrates from stormwater management ponds, Water Air Soil Pollut. 2007, 178 (1-4), 69-77.

[22] J.W. Snodgrass, R. E. Casey, D. Joseph, J. A. Simon, Microcosm investigations of stormwater pond sediment toxicity to embryonic and larval amphibians: Variation in sensitivity among species, Environ. Pollut. 2008, 154 (2), 291-297.

[23] L. Behrendt, Aquatic and riparian vegetation in SUDS ponds, in SUDS in Scotland - the monitoring programme (Ed.: C. Jeffries), SNIFFER, Edinburgh 2003.

[24] M. Hennessy, Aquatic ecology and SUDS ponds, with reference to the ponds at DEX, in Proceedings of the twenty-sixth meeting of the Standing Conference on Stormwater Source Control, Coventry University, Coventry 2004.

[25] K. Vermonden, R. Leuven, G. van der Velde, Environmental factors determining invasibility of urban waters for exotic macroinvertebrates, Divers. Distrib. 2010, 16 (6), 1009-1021.

[26] C. Jefferies, A. Spitzer, A. Duffy, The DEX monitoring programme, in Proceedings of the twenty-sixth meeting of the Standing Conference on Stormwater Source Control, Coventry University, Coventry 2004.

[27] J. Lancaster, F. Edwards, K. Hall, A. Hogan, N. Towers, S. Townsend, Duloch Park Remediation Ponds Biomonitoring 1999-2003 Final report, University of Edinburgh, Edinburgh 2004.

[28] Pond Action, A guide to the methods of the National Pond Survey, Pond Action, Oxford 1998.

[29] R Development Core Team, $R$ : A language and environment for statistical computing, R Foundation for Statistical Computing, Viennia, Austria 2012.

[30] K. R. Clarke, Non-parametric multivariate analyses of changes in community structure, Aust. J. Ecol. 1993, $18,117-143$.

[31] R. J. Layton, J. R. Voshell, Colonization of new experimental ponds by benthic macroinvertebrates, Environ. Entomol. 1991, 20, 110-117.

[32] P. Williams, M. Whitfield, J. Biggs, How can we make new ponds biodiverse? A case study monitored over 7 years, Hydrobiologia 2008, 597, 137-148.

[33] Ponds Conservation Trust: Policy and Research, Maximising the ecological benefits of SUDS schemes, Ponds Conservation Trust: Policy and Research, Oxford 2003.

[34] S. D. Rundle, A. Foggo, V. Choiseul, D. T. Bilton, Are distribution patterns linked to dispersal mechanism? An investigation using pond invertebrate assemblages, Freshwater Biol. 2002, 47, 1571-1581.

[35] M. J. Jeffries, Measuring Talling's 'element of chance in pond populations', Freshwater Biol. 1989, 21, 383393.

[36] M. Jeffries, Small ponds and big landscapes: the challenge of invertebrate spatial and temporal dynamics 
for European pond conservation, Aquat. Conserv. Mar. Freshwater Ecosyst. 2005, 15 (6), 541-547.

[37] M. Canedo-Arguelles, M. Rieradevall, Early succession of the macroinvertebrate community in a shallow lake: Response to changes in the habitat condition, Limnologica 2011, 41 (4), 363-370.

[38] A. Ruhi, D. Boix, S. Gascon, J. Sala, X. D. Quintana, Nestedness and successional trajectories of macroinvertebrate assemblages in man-made wetlands, Oecologia 2013, 171 (2), 545-556.

[39] C. F. Mason, Biology of Freshwater Pollution, 4th Ed., Pearson Education, Harlow 2002.

[40] K. Heal, N. McLean, B. D'Arcy, SUDS and sustainability, in Proceedings of the twenty-sixth meeting of the Standing Conference on Stormwater Source Control, Coventry University, Coventry 2004. 
Table 1. Summary characteristics of urban drainage sites studied (adapted from [3]).

\begin{tabular}{lllll}
\hline Characteristic & Halbeath & Linburn & Pond 7 & Calais burn wetland \\
\hline Catchment land-use & Leisure development, & Residential, & Residential, & Residential, parkland, \\
& highway & highway, grassland & highway & highway \\
Catchment area (ha) & 13.5 & 67.5 & 67 & 197 \\
Date of construction & 1997 & 1998 & 1998 & 1998 \\
Surface area (m $\left.{ }^{2}\right)$ & 6489 & 9848 & 4992 & 18633 \\
Mean depth (m) & 1.49 & 2.24 & 1.15 & 0.94 \\
\hline
\end{tabular}

Table 2. Summary of invertebrate species lost from SUDS sites sampled between 2007 and 2011. See text for definition of species loss.

\begin{tabular}{|c|c|c|c|c|}
\hline Site & Halbeath & Linburn & $\begin{array}{l}\text { Calais Burn } \\
\text { wetland }\end{array}$ & Pond 7 \\
\hline Species lost & $\begin{array}{l}\text { Hydroporus } \\
\text { obsoletus } \\
\text { Hyphydrus ovatus }\end{array}$ & $\begin{array}{l}\text { Hyphydrus ovatus } \\
\text { Lymnaea peregra }\end{array}$ & $\begin{array}{l}\text { Hygrotus inaequalis } \\
\text { Nebrioporus } \\
\text { elegans } \\
\text { Ilybius fuliginosus } \\
\text { Haliplus confinis } \\
\text { Ocetis bicolor } \\
\text { Limnephilus stigma } \\
\text { Agrypnia obsoleta } \\
\text { Planorbis vortex }\end{array}$ & $\begin{array}{l}\text { Corixa panzeri } \\
\text { Haliplus } \\
\text { lineatocollis } \\
\text { Helophorus grandis } \\
\text { Limnephilus politus } \\
\text { Lymnaea stagnalis }\end{array}$ \\
\hline
\end{tabular}


Table 3. Summary of the top five invertebrate species identified by SIMPER analysis as most strongly influencing between site dissimilarity of community composition at different SUDS sites.

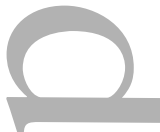

\begin{tabular}{llll}
\hline & Halbeath & Linburn & Calais Burn wetland \\
\hline Linburn & Chaoborous crystallinus & & \\
& Asellus aquaticus & & \\
& Potamopyrgus antipodarum & & \\
& Gammarus pulex & & \\
& Lymnaea peregra & & \\
Wetland & Potamopyrgus antipodarum & Radix balthica & \\
& Chaoborous crystallinus & Potamopyrgus antipodarum & \\
& Phyrganea bipunctata & Gammarus pulex & \\
& Cloeon dipterum & Lymnaea stagnalis & Asellus aquaticus \\
& Enallagma cyathigerum & Cloeon dipterum & Corixa punctata \\
& Potamopyrgus antipodarum & Radix balthica & Nebrioporus elegans Lymnaea \\
& Chaoborus crystallinus & Sigara concinna & peregra \\
& Corixa punctata & Lymnaea stagnalis & Hesperocorixa sahlbergi \\
& Asellus aquaticus & Corixa punctata & Physa fontinalis \\
& Hesperocorixa sahlbergi & &
\end{tabular}



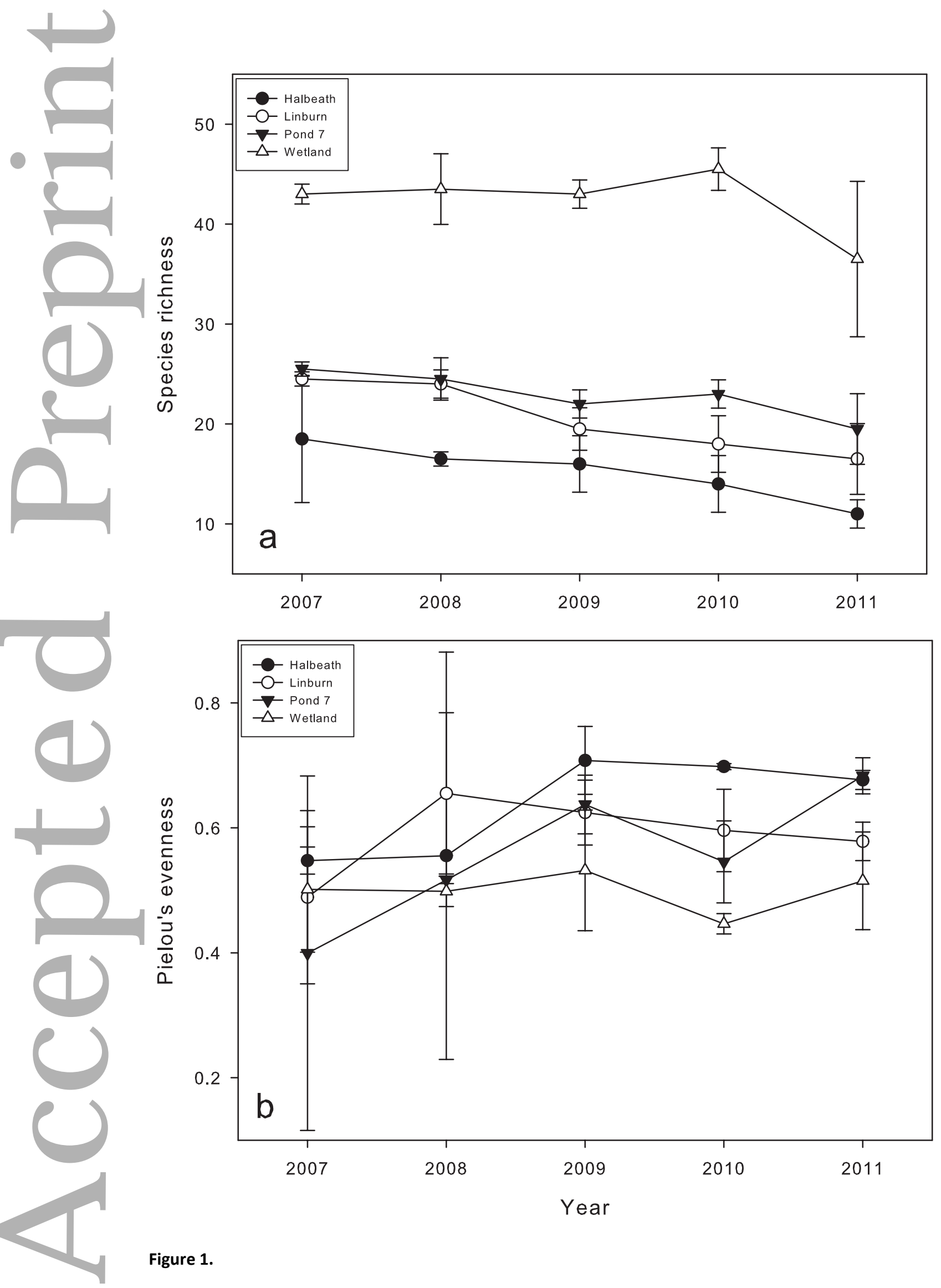

Figure 1. 


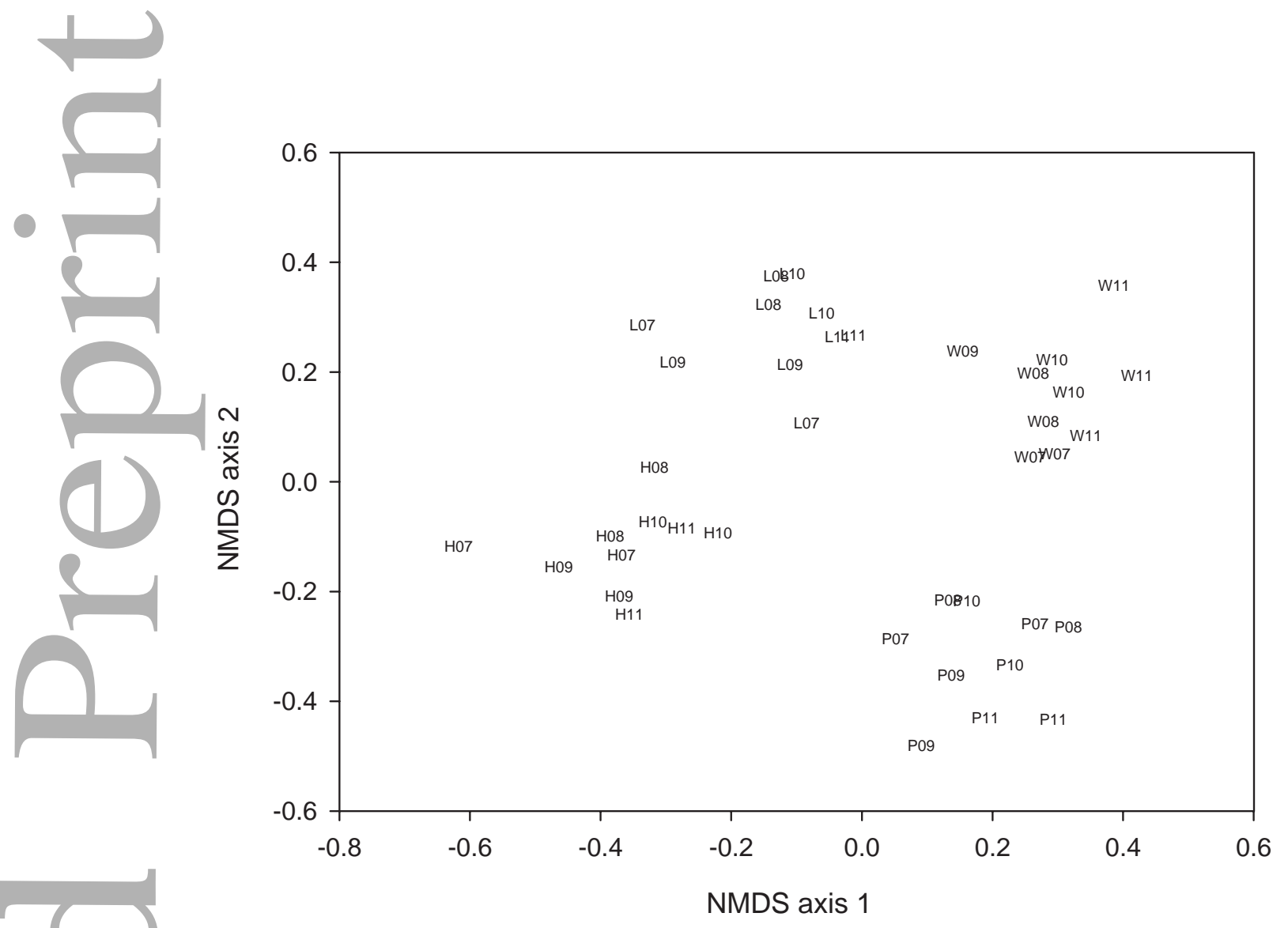

Figure 2. 


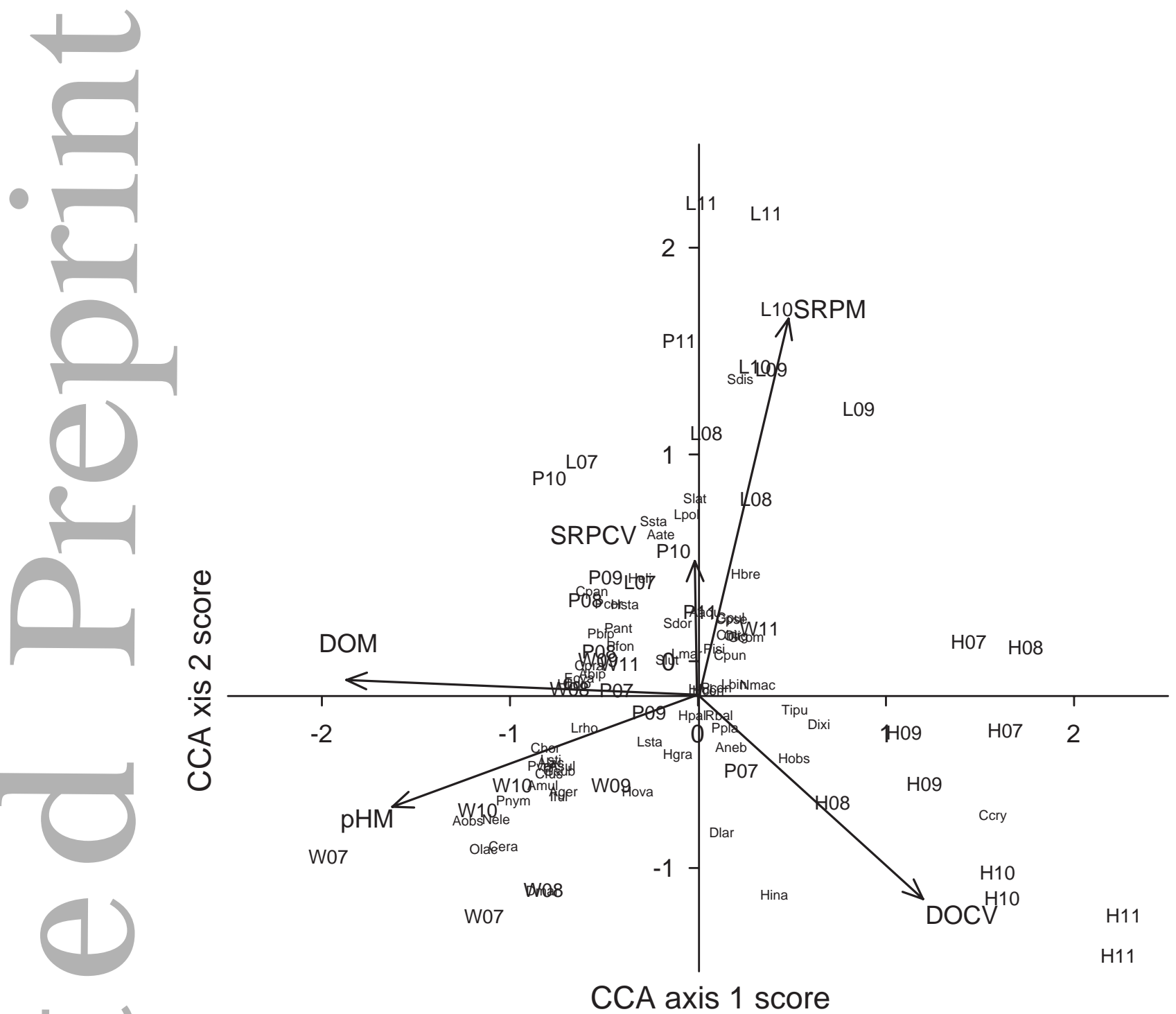

Figure 3. 
Table 4. Summary of chemical water quality parameters measured at the SUDS sites between 2007 and 2011. Values given are means, with coefficient of variation in parentheses, across all years combined. Stars indicate the significance values from mixed-model ANOVA of between site differences and Levene’s test of equality of variances between sites (see text for details), $*<0.05, * *<0.01, * * *<0.001$.

\begin{tabular}{|c|c|c|c|c|c|c|}
\hline \multirow[t]{2}{*}{ Parameter } & \multicolumn{4}{|l|}{ Site } & \multirow[t]{2}{*}{ Site difference } & \multirow{2}{*}{$\begin{array}{l}\text { Equality of variance } \\
\text { between sites }\end{array}$} \\
\hline & Halbeath & Linburn & Pond 7 & Calais Burn wetland & & \\
\hline $\mathrm{pH}$ & $7.3(4.6)$ & $7.6(4.4)$ & $7.6(3.9)$ & $7.9(4.2)$ & $* * *$ & \\
\hline Conductivity $\left(\mu \mathrm{S} \mathrm{cm}{ }^{-1}\right)$ & $752.7(64.7)$ & 588.7 (29.6) & $614.8(34.2)$ & $539.4(20.5)$ & & $* * *$ \\
\hline $\begin{array}{l}\text { Dissolved oxygen } \\
\text { saturation (\%) }\end{array}$ & $47.1(42.3)$ & $77.5(15.0)$ & $90.1(15.6)$ & $95.2(18.6)$ & $* * *$ & $*$ \\
\hline Nitrate $\left(\mathrm{mg} \mathrm{L}^{-1}\right)$ & 92.5 (150.5) & 210.8 (89.7) & $118.2(162.6)$ & $146.7(206.5)$ & $* * *$ & \\
\hline Nitrite (mg L ${ }^{-1}$ ) & $12.2(114.5)$ & $11.0(43.1)$ & $8.1(99.5)$ & $6.9(88.7)$ & $* * *$ & $* *$ \\
\hline Ammonia (mg L ${ }^{-1}$ ) & $98.2(166.4)$ & $190.3(195.4)$ & $61.8(117.3)$ & $68.3(99.4)$ & $* * *$ & \\
\hline $\begin{array}{l}\text { Soluble reactive } \\
\left.\text { phosphorus (mg } L^{-1}\right) * * *\end{array}$ & $16.0(68.7)$ & $57.4(76.3)$ & $22.4(77.9)$ & $11.8(65.9)$ & $* * *$ & $* * *$ \\
\hline
\end{tabular}


Figure 1 Changes in a) species richness and b) Pielou's evenness of SUDS sites between 2007 and 2011. Values shown are means +/- standard deviation.

Figure 2 Two-dimensional non-metric multidimensional scaling plot of dissimilarity (Bray-Curtis index) of invertebrate communities. Two-dimensional stress $=0.159$. Site codes $\mathrm{H}=$ Halbeath, $\mathrm{L}=\mathrm{Linburn}, \mathrm{P}=\mathrm{Pond} 7$ and $\mathrm{W}=$ Calais Burn wetland; numbers following indicate year of sampling.

Figure 3 Plot of the first two axes from a canonical correspondence analysis of invertebrate abundance and physico-chemical data. Site codes $\mathrm{H}=$ Halbeath, $\mathrm{L}=$ Linburn, $\mathrm{P}=$ Pond 7 and $\mathrm{W}=$ Calais Burn wetland; numbers following indicate year of sampling. SRP = soluble reactive phosphorus, DO = dissolved oxygen. Variables ending in M indicate influence of mean values, those ending in CV the influence of the coefficient of variation in the relevant variable. A full list of species codes is given in Supporting Information Table S1. 